Check for updates

Cite this: RSC Adv., 2017, 7, 21180

\title{
Combined mechanochemical and thermal treatment of PCBs contaminated soil
}

\author{
Zhonghua Zhao, (D) Mingjiang Ni, Xiaodong Li, ${ }^{\star}$ Alfons Buekens and Jianhua Yan
}

This study combines a preliminary mechanochemical treatment and a subsequent thermal desorption for remediating soil, contaminated with polychlorinated biphenyls (PCBs). After 2 hours of grinding, assisted by addition of $\mathrm{SiO}_{2}$, the total concentration of PCBs and their TEQ-value decreased by $81.9 \%$ and $85.4 \%$, respectively. The effect of thermal treatment at 400,500 and $600{ }^{\circ} \mathrm{C}$ on the removal efficiency of PCBs from ground soil was then investigated. The residual amount of PCBs reduced with the rising temperature and dropped to $137 \mathrm{ng} \mathrm{g}^{-1}$ in the treated soil when the treatment temperature reached $600{ }^{\circ} \mathrm{C}$, equivalent to a desorption efficiency of $99.85 \%$ and a removal efficiency of nearly $100 \%$. The formation of polychlorinated dioxins and dibenzofurans (PCDD/Fs) was also monitored: PCDDs and PCDFs were generated, particularly at $400{ }^{\circ} \mathrm{C}$, however their formation weakened at higher temperatures and hydrodechlorination dominated.

Received 6th February 2017 Accepted 27th March 2017

DOI: 10.1039/c7ra01493g

rsc.li/rsc-advances substrate for hydrodechlorination. A mixture of metallic calcium and calcium oxide was found the most suitable degradation agent for degrading chlorinated contaminants. A simple preliminary washing under ultrasonication facilitated the following degradation. ${ }^{9}$ The preferred reactants are $\mathrm{CaO}$ and $\mathrm{SiO}_{2}$, because they are cheap and their reaction products can be dealt with safely. Debromination of hexabromobenzene proceeded smoothly with an increase in the molar ratio of $\mathrm{CaO}$ addition, and almost complete debromination was achieved after 6 hours of grinding with a molar ratio $\mathrm{Ca}$ : Br kept constant at $2: 1 .^{10}$ Iron powder and quartz sand were best for intensifying the destruction of mirex, an insecticide based on hexachlorocyclopentadiene, which was destroyed completely after 2 hours grinding at a charge ratio of $36: 1$ (reagent $/$ mirex, $\mathrm{m} / \mathrm{m}){ }^{\mathbf{1 1}}$

Due to PCBs' special physical and chemical properties, $\mathrm{Nah}^{\mathbf{1 2}}$ assessed the potential of mechanochemical methods of removal, using fine metal powder for removing PCBs from waste insulating oil. After treatment for 4 hours at room temperature with a dosage of $1.53 \mathrm{~mol}$ metal per $\mathrm{kg}$ oil, only $70 \%$ PCBs removal was achieved when zinc was added. Hydrodechlorination of pure 3-chlorobiphenyl (3-MCP) was conducted by Zhang. ${ }^{13}$ The residual 3-MCP in the sample decreased rapidly within 20 minutes and diminished more gradually with further grinding. After 6 hours of grinding, over 99.5\% 3-MCP was decomposed, but the weight ratio of 3-MCP to the inorganic powder was merely $5 \%$. When the method was applied to soil contaminated with PCBs, 20 hours of grinding were required to attain a PCBs removal efficiency of $98 \% .^{14}$

Thermal desorption was therefore considered as a subsequent treatment process in order to save MC-treatment time and improve removal efficiency. Because highly chlorinated PCBs were broken down into lower chlorinated ones during the 
mechanochemical treatment, which had lower boiling points, the thermal treatment could more easily eliminate them. Also, the risk of a de novo synthesis of high amounts of PCBs and dioxins was lowered.

Thermal desorption is essentially a thermally induced physical separation process. Organic pollutants are vaporised from a solid matrix and then transferred into a carrier gas stream. In contrast with treatment by incineration, the decomposition of organic contaminants is not the immediate result desired. The contaminants in the gas stream may eventually be condensed, burned in an afterburner or cleaned by carbon adsorption. ${ }^{15}$ However, depending on operating temperature and strength of desorption, these liberated contaminants may still need to be degraded or converted during treatment. ${ }^{16}$ During thermal desorption, synergetic treatment with the addition of zero-valent iron nano-powder or basecatalysed additives effectively enhanced desorption and decomposition. ${ }^{17,18}$ However, the processes developed for chlorinated compounds caused the additional formation of polychlorinated dioxins and dibenzofurans (PCDD/Fs), which are often accompanied by higher toxic equivalency ${ }^{19}$ especially in the presence of oxygen..$^{20}$

The combined use of mechanochemical hydrodechlorination and thermal desorption was studied. Highly chlorinated contaminants were degraded by grinding and treatment time was reduced by the subsequent use of thermal desorption. The combined decontamination effects of these two methods were investigated. All 209 PCBs congeners and 12 toxic dl-PCBs as well as their TEQ were presented for analysis. Additionally, PCDD/Fs were analysed to evaluate the evolution of the dioxins during treatment. This has allowed differentiation between the original PCBs and their PCDD/Fs content, those that remained after milling, and the final residual PCBs and PCDD/Fs.

\section{Materials and methods}

\subsection{Materials}

Soil from a PCBs storage site in Zhejiang province, China, was used in this study. It was contaminated due to leakage from discarded transformers and capacitors. Its initial PCBs concentration was $505 \mu \mathrm{g} \quad \mathrm{g}^{-1}$. Tri-(TrCBs) and tetrachlorobiphenyls (TeCBs) were the predominant homologues groups, since their sum accounted for $90 \mathrm{wt} \%$ of total PCBs concentration. Their composition was similar to Aroclor 1248 and Kanechlor KC 400 , as presented by Huang. ${ }^{21}$

Calcium oxide and quartz used as additives during grinding were purchased from Sinopharm Chemical Reagent Co., Ltd. China, and used without treatment.

\subsection{Apparatus and methods}

A planetary ball mill (XQM-0.4L, Kexi, China) was used for grinding a mixture of soil and additives: $5 \mathrm{~g}$ of contaminated soil was mixed together with $5 \mathrm{~g} \mathrm{CaO}$ and $10 \mathrm{~g} \mathrm{SiO}_{2}$. The total $20 \mathrm{~g}$ of this mixture was added to a stainless steel pot containing $200 \mathrm{~g}$ of stainless steel balls. The planetary ball mill operated under atmospheric conditions for 2 hours at a speed of $400 \mathrm{rpm}$. To prevent over-heating, the milling paused for 30 minutes after every 30 minutes of grinding.

After 2 hours of effective milling, the sample was taken out and then thermally treated. The thermal desorption system contained three major parts (Fig. 1): a carrier gas flow system, a horizontal tubular reactor and electric furnace, and a trap for collecting PCBs and PCDD/Fs from the exhaust gas. The trap was composed of a XAD-2 absorption tube and two toluene absorption bottles in series. During each test, $2 \mathrm{~g}$ of grinded soil was heated for 40 minutes at 400,500 and $600^{\circ} \mathrm{C}$ in a flow of $400 \mathrm{~mL} \mathrm{~min}{ }^{-1}$ high purity nitrogen $(\geq 99.99 \%)$. Evaporated PCBs and PCDD/Fs were carried by the $\mathrm{N}_{2}$ flow and then captured by the trap system. After thermal treatment, both the soil and the gas phase were collected and their PCBs and PCDD/Fs were detected and analysed. The thermal desorption procedures and apparatus have been described in full detail in former studies. ${ }^{18}$

\subsection{PCBs, PCDD/Fs analysis}

The grinded soil and the thermally treated soil, as along with the XAD-2 that had been collected after treatment, were extracted with toluene for 24 hours. Thereafter, the PCBs samples were cleaned up serially by percolation through a multi-silica gel column and a Florisil column. All sample clean-up procedures were conducted according to the EPA 1668 method. The PCDD/Fs samples were cleaned up using a multisilica gel column and an alkaline alumina column in succession on the basis of the EPA method 1613. PCBs and PCDD/Fs were separated, identified and quantified by HRGC/HRMS (JEOL JMS-800D, Japan), equipped with a DB-5MS column (60 $\mathrm{m} \times$ $0.25 \mathrm{~mm} \times 0.25 \mu \mathrm{m})$. All 209 PCBs congeners and $136 \mathrm{PCDD} / \mathrm{Fs}$ congeners were detected.

\subsection{QA \& QC}

For the quantification of PCBs and PCDD/Fs, three distinct ${ }^{13} \mathrm{C}$ labeled standard solutions were added before Soxhlet extraction, before purification and then before analysis. All recovery rates of each internal standard were in accordance with the usual analytical recovery requirements.

Some repeated experimental conditions were performed. The results reported for the gas phase were expressed based on the initial weight of contaminated soil.

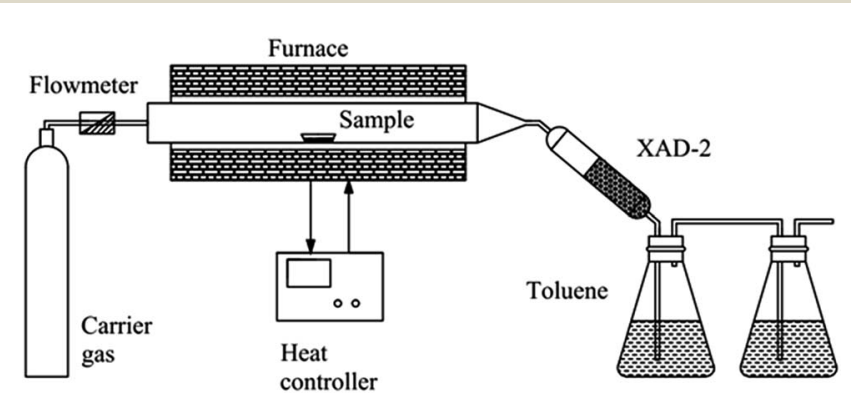

Fig. 1 Schematic diagram of the experiment apparatus. 


\subsection{Degradation, desorption and removal efficiency}

Degradation efficiency was calculated to assess the degree of PCBs decomposition after the mechanochemical treatment:

$$
\begin{aligned}
\text { Degradation efficiency }= & \frac{\mathrm{PCB}(\text { raw soil })-\mathrm{PCB}(\text { grinded soil })}{\mathrm{PCB}(\text { raw soil })} \\
& \times 100 \%
\end{aligned}
$$

The desorption efficiency for assessing the performance of the thermal treatment was calculated by:

$$
\begin{aligned}
& \text { Desorption efficiency }= \\
& \frac{\operatorname{PCB}(\text { grinded soil })-\mathrm{PCB}(\text { grinded }+ \text { thermally treated soil })}{\mathrm{PCB}(\text { grinded soil })} \\
& \quad \times 100 \%
\end{aligned}
$$

To evaluate the combined decontamination of PCBs, removal efficiency was defined and calculated as:

$$
\begin{aligned}
& \text { Removal efficiency }= \\
& \frac{\mathrm{PCB}(\text { raw soil })-\mathrm{PCB}(\text { grinded }+ \text { thermally treated soil })}{\mathrm{PCB}(\text { raw soil })} \\
& \times 100 \%
\end{aligned}
$$

where $\mathrm{PCB}$ (raw soil) is the initial PCBs concentration in raw soil; $\mathrm{PCB}$ (grinded soil) represents the residual PCBs concentration in grinded soil; and $\mathrm{PCB}$ (grinded + thermally treated soil) stands for the residual PCBs concentration in the soil after combined treatment.

\subsection{Weight average chlorination degree}

The weight average chlorination degree reflects the average extent and depth of chlorination of all PCBs or PCDD/Fs congeners. It is calculated by

$$
\text { Chlorination degree }=\frac{\sum C_{\mathrm{j}} \times n_{\mathrm{j}}}{\sum C}
$$

where $C_{\mathrm{j}}$ stands for the concentration of each PCBs or PCDD/Fs isomer group and $n_{\mathrm{j}}$ for the number of chlorine atoms of each PCBs or PCDD/Fs homologue group; $C$ corresponds to the total concentration of PCBs or PCDD/Fs.

\section{Results and discussion}

\subsection{Degradation effect of ball milling}

Numerous studies have demonstrated the feasibility of the mechanochemical method as a potential and promising technique for degrading POPs., ${ }^{3,9,22}$

PCBs samples were decomposed mechanochemically through hydrodechlorination by grinding jointly with $\mathrm{CaO} .^{23,24}$ In this study, the PCBs-contaminated soil was first grinded for 2 hours at $400 \mathrm{rpm}$ together with $\mathrm{CaO}$ and $\mathrm{SiO}_{2}$. The residual PCBs, dl-PCBs and TEQ-values found in the soil after grinding are listed in Table 1.

After 2 hours of grinding, the total amount of PCBs in the soil decreased from $505 \mu \mathrm{g} \mathrm{g}^{-1}$ to $91.2 \mu \mathrm{g} \mathrm{g}^{-1}$, attaining a degradation efficiency of $81.9 \%$. The residual dl-PCBs concentration in grinded soil was $2.4 \mu \mathrm{g} \mathrm{g}^{-1}$, corresponding with a degradation efficiency of $87.5 \%$, while the degradation efficiency of their WHOTEQ reached $85.4 \%$. Compared with the soil that included only the $\mathrm{CaO}$, the addition of $\mathrm{SiO}_{2}$ improved the degradation efficiency of all samples. These results accord with the study of Zhang, ${ }^{13}$ who found that the addition of quartz to the grinding mix facilitated hydrodechlorination of 3-MCP, especially in cases with a higher weight ratio than $10 \%$ of $3-\mathrm{MCP}$ to $\mathrm{CaO}$.

After 2 hours of grinding, a degradation efficiency of $81.9 \%$ was attained, but the treatment times required are too long if the destruction should be augmented much further. After 5 hours of grinding, about $0.75 \%$ of the original PCPs were left in the treated soil, but during the next 5 hour treatment, the degradation efficiency of PCPs was only up by $0.66 \% .^{7}$ So, for the purpose of reducing the treatment time, thermal desorption was introduced for further remediation.

\subsection{PCBs removal during thermal treatment}

3.2.1 Desorption and removal efficiencies of PCBs. Various studies $^{25,26}$ on thermal desorption have shown that temperature significantly affects the removal of organic pollutants. Treatment temperature should be optimised, considering both desorption efficiency and energy consumption. The ideal treatment efficiency cannot be reached at a low temperature, ${ }^{27}$ but if the temperature is too high, the soil's texture will be destroyed and the cost of fuel will become unacceptable. In this study, the temperature varied from 400 to $600{ }^{\circ} \mathrm{C}$ and the treatment time was kept constant at 40 minutes. $\mathrm{Qi}^{28}$ also tested a shorter treatment period of 20 minutes, but the desorption efficiency remained disappointingly low.

Table 2 shows the amount of PCBs in both soil and gas phases, as determined after thermal desorption. The total residual amount of PCBs remaining in the treated soil lessened with the rising treatment temperature. After treatment at $600{ }^{\circ} \mathrm{C}$, the residual PCBs concentration dropped to $137 \mathrm{ng} \mathrm{g}^{-1}$ and the desorption efficiency rose up to $99.85 \%$, to be compared with $99.8 \%$ at a furnace temperature of $500{ }^{\circ} \mathrm{C}$ and with $96.45 \%$ at $400{ }^{\circ} \mathrm{C}$. All desorption efficiency values are much higher than the earlier efficiency values, obtained in our previous studies, yet without preliminary grinding. ${ }^{29}$

There are three reasons that could possibly account for the difference: (a) after grinding, the larger particles $(420-841 \mu \mathrm{m})$ were converted into finer ones $(<150 \mu \mathrm{m})$ and decontaminated more deeply than the initial coarser particles; ${ }^{29}$ (b) PCBs molecules were gradually degraded during grinding, producing lower chlorinated species with lower boiling points, and therefore desorbed more easily from the solid matrix when heated; (c) compared with the soil being heated directly, moisture in the soil after grinding was absorbed by $\mathrm{CaO}$, converting it into $\mathrm{Ca}(\mathrm{OH})_{2}$ and both $\mathrm{CaO}$ and $\mathrm{Ca}(\mathrm{OH})_{2}$ facilitated the hydrodechlorination and destruction of PCBs. ${ }^{16,30}$

The removal efficiency based on the initial concentration of PCBs present in the raw soil is also represented in Table 2. Considerable removal efficiency was achieved by suitably combining the mechanochemical treatment with thermal 
Table 1 Residual PCBs, dl-PCBs and TEQ in grinded soil after mechanochemical grinding

\begin{tabular}{|c|c|c|c|c|c|c|c|}
\hline Additives & $\mathrm{PCBs}^{a}$ & Degradation efficiency $^{b}$ & $\begin{array}{l}\text { Chlorination } \\
\text { degree }\end{array}$ & $\mathrm{dl}-\mathrm{PCBs}^{a}$ & Degradation efficiency $^{b}$ & $\mathrm{TEQ}^{c}$ & Degradation efficiency ${ }^{b}$ \\
\hline $\mathrm{CaO}$ & 148.5 & 70.6 & 3.86 & 8.2 & 56.5 & 2.1 & 64 \\
\hline
\end{tabular}

Table 2 Thermal desorption of grinded soil at different temperatures

\begin{tabular}{llll}
\hline & $400{ }^{\circ} \mathrm{C}$ & $500{ }^{\circ} \mathrm{C}$ & $600{ }^{\circ} \mathrm{C}$ \\
\hline Soil $^{a}$ & $3230 \pm 150$ & $166 \pm 13$ & $137 \pm 6$ \\
Gas $^{a}$ & 3490 & 5010 & 4320 \\
Desorption efficiency $^{b}$ & 96.45 & 99.8 & 99.85 \\
Removal efficiency $^{b}$ & 99.36 & 99.97 & 99.97 \\
${ }^{a}$ Unit: ng g
\end{tabular}

desorption: a removal efficiency of $99.36 \%$ was obtained after heating for 40 minutes at only $400{ }^{\circ} \mathrm{C}$. When increasing the thermal treatment temperature to $600{ }^{\circ} \mathrm{C}$, removal efficiency even approached $100 \%$. These results indicate that combining the two techniques is feasible for remediating PCBscontaminated soil, a proposition that considerably improves the PCBs removal efficiency reached by thermal desorption, after a relatively short time of mechanochemical pretreatment.

3.2.2 PCBs isomer distribution in treated soil. Fig. 2a compares the amount of PCBs congeners in raw soil and treated soil. As in raw soil, TrCBs and TeCBs in grinded soil still dominate among the PCBs homologues, accounting for $32.9 \%$ and $58.5 \%$, respectively. Higher chlorinated PCBs homologues (HpCBs and above) are not discussed here because they comprised less than $0.5 \%$ of the total quantity of PCBs. The amount of all homologues dropped drastically after thermal treatment, especially that of the higher chlorinated PCBs.

The proportion of low chlorinated PCBs homologues increased after thermal treatment, while the highly chlorinated PCBs homologues showed the opposite trend. As the temperature rises, this variation becomes even more pronounced, consistent with the findings from Qi. ${ }^{29}$ After heating for 40 minutes at $600{ }^{\circ} \mathrm{C}$, the fraction of MCBs in the grinded soil rose from $0.09 \%$ to $4.57 \%$, DiCBs from $1.8 \%$ to $12.97 \%$, and TrCBs also increased from $32.9 \%$ to $50.84 \%$. In contrast, the proportion of TeCBs decreased from $58.5 \%$ to $28.70 \%$ and that of PeCBs reduced from $6.2 \%$ to $2.55 \%$.

At the same time, the weight average chlorination degree of PCBs in the treated soil lessened gradually as the temperature rose, as observed in Fig. 2a. Initially, it was still 3.71 in the grinded soil and decreased to 3.13 after heating for 40 minutes at $600{ }^{\circ} \mathrm{C}$, demonstrating strong hydrodechlorination during thermal desorption. Possible decomposition pathways were presented by He. ${ }^{31}$

3.2.3 PCBs isomer distribution in the gas phase. During thermal treatment, PCBs are vaporised and thus separated from the solid matrix. A carrier gas transfers these to off-gas treatment. $^{32}$ Fig. $2 \mathrm{~b}$ represents the amount of various PCBs homologues reporting to the gas phase. Their total amount enlarged from $3490 \mathrm{ng} \mathrm{g}^{-1}$ at $400{ }^{\circ} \mathrm{C}$ to $5010 \mathrm{ng} \mathrm{g}^{-1}$ at $500{ }^{\circ} \mathrm{C}$, yet then declined to $4320 \mathrm{ng} \mathrm{g}^{-1}$ at $600{ }^{\circ} \mathrm{C}$. The higher temperature desorbs more PCBs from the soil matrix. Conversely, high temperatures also accelerate destruction, leading to reduced quantities of PCBs in the gas phase once the temperature rises over $500{ }^{\circ} \mathrm{C}$. The total amount of PCBs in both the soil and the gas were $6720 \mathrm{ng} \mathrm{g}^{-1}$ at $400{ }^{\circ} \mathrm{C}, 5170 \mathrm{ng} \mathrm{g}^{-1}$ at $500{ }^{\circ} \mathrm{C}$ and 4460 ng $\mathrm{g}^{-1}$ at $600{ }^{\circ} \mathrm{C}$ (Table 2). After heating, the PCBs concentration levels of all samples were lower than that had been in the soil before thermal desorption. These results suggest that desorption as well as hydrodechlorination and destruction, occurs simultaneously during thermal treatment.

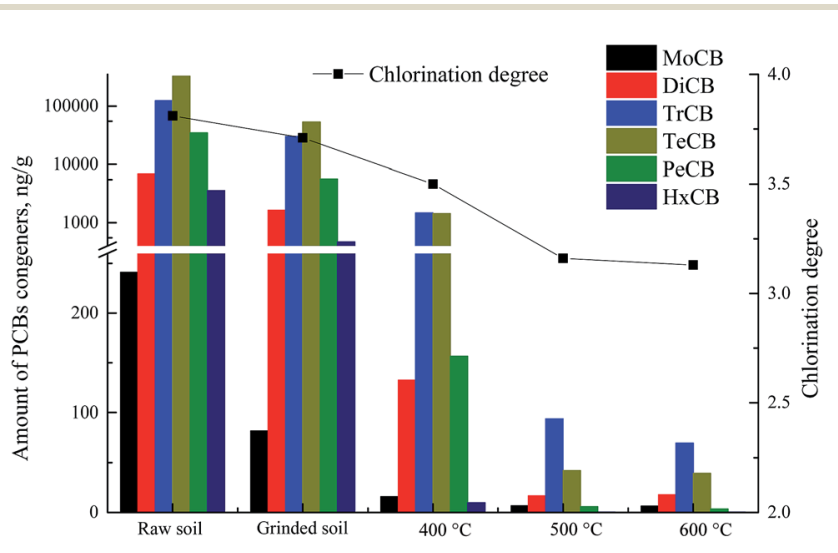

(a)

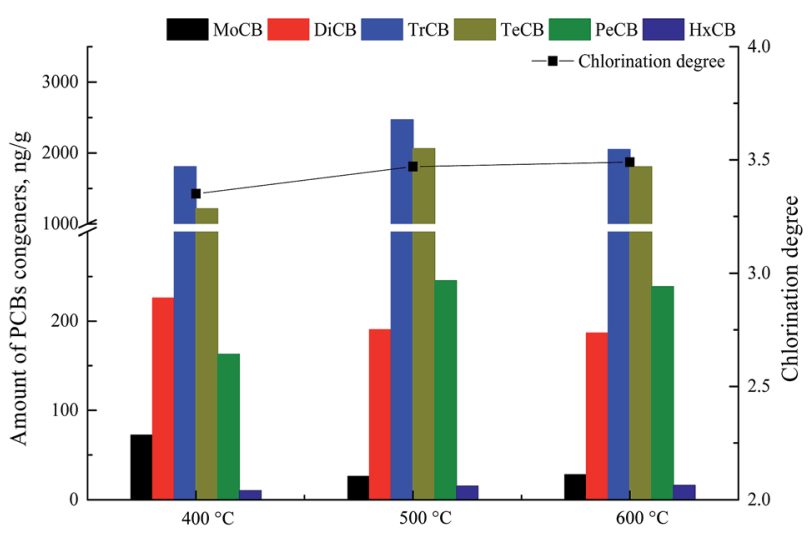

(b)

Fig. 2 Amount of PCBs isomers in soil (a) and in flue gas (b) for three temperatures. 
The weight average chlorination degree of PCBs in the gas varied rather little, from 3.35 at $400{ }^{\circ} \mathrm{C}$ to 3.49 at $600{ }^{\circ} \mathrm{C}$, in contrast with the tendency seen in the soil. This may be due to soil minerals promoting contaminant decomposition.

Still, large amounts of PCBs are transferred from the soil matrix to the off-gas, though destruction, decomposition and hydrodechlorination all occur. Further treatments such as dust extraction, vapour condensation and adsorption of POPs are therefore required to decrease the concentration of contaminants in the off-gas to meet the emissions requirements prior to discharge. ${ }^{33,34}$

3.2.4 dl-PCBs in treated soil and flue gas. Dioxin-like PCBs (dl-PCBs) include 12 coplanar PCBs, which show similar toxicity to that of PCDD/Fs. ${ }^{35}$ Their concentration reached $18.9 \mu \mathrm{g} \mathrm{g}^{-1}$ in the raw soil. Three major contributors, namely $3,3^{\prime}, 4,4^{\prime}-\mathrm{TeCB}$

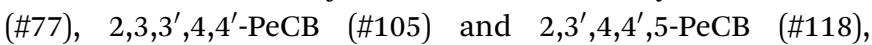
accounted for $91 \%$ of the total dl-PCBs, in weight units. The total amount of dl-PCBs dropped to $2.4 \mu \mathrm{g} \mathrm{g}^{-1}$ after 2 hours of grinding, attaining a degradation efficiency of $87.5 \%$ (Table 3 ).

Both the desorption efficiency and removal efficiency of dlPCBs improve within a temperature range of 400 to $600{ }^{\circ} \mathrm{C}$. The desorption efficiency of dl-PCBs reaches $99.97 \%$ at $600{ }^{\circ} \mathrm{C}$, clearly higher than the desorption efficiency of all PCBs at the same temperature. The removal efficiency of dl-PCBs approaches $100 \%$ after grinding for 2 hours and heated at $600{ }^{\circ} \mathrm{C}$ for 40 minutes. The dl-PCBs consist of relatively high chlorinated PCBs, which explains the higher desorption efficiency value.

The World Health Organization (WHO) toxic equivalence factors (TEFs) are used to calculate the WHO-TEQ contributions for PCBs, ${ }^{36}$ and this was 5760 pg WHO-TEQ per $g$ in the raw soil. After ball milling, the TEQ dropped to $839 \mathrm{pg}$ WHOTEQ per $\mathrm{g}$ (degradation efficiency of $85.4 \%$ ), and then further decreased to $0.77 \mathrm{pg}$ WHO-TEQ per $\mathrm{g}$ after thermal treatment at $600{ }^{\circ} \mathrm{C}$ for 40 minutes, attaining a removal efficiency of $99.99 \%$.

\subsection{Formation of PCDD/Fs during treatment}

3.3.1 PCDD/Fs concentration in soil and off gas. The formation of PCDD/Fs is a serious and inevitable issue in traditional thermal treatment, which has been well investigated ever since they were first detected in the fly ash of an incinerator decades ago. ${ }^{37}$ PCBs can be oxidised to more toxic PCDFs, ${ }^{19}$ meaning that the evaluation of PCDD/Fs formation is particularly important for any PCBs treatment technique.

As represented in Fig. 3, the concentration of PCDDs and PCDFs in the raw soil were $1430 \mathrm{pg} \mathrm{g}^{-1}$ and $5250 \mathrm{pg} \mathrm{g}^{-1}$, respectively, and decreased to $713 \mathrm{pg} \mathrm{g}^{-1}$ and $903 \mathrm{pg} \mathrm{g}^{-1}$ after 2 hours of grinding treatment. After thermal treatment at $400{ }^{\circ} \mathrm{C}$, both levels increased, especially PCDFs, to $6990 \mathrm{pg} \mathrm{g}^{-1}$, nearly 7 times higher than that in grinded soil. The results indicate that PCDDs and PCDFs were generated, in particular at $400{ }^{\circ} \mathrm{C}$. When the treatment temperature rises to 500 or $600{ }^{\circ} \mathrm{C}$, the concentration again drops, since $500{ }^{\circ} \mathrm{C}$ is higher than the optimum PCDD/Fs generation temperature, ${ }^{38}$ and higher temperatures facilitate the degradation and decomposition of PCDD/Fs.

Table 4 lists the concentration of PCDDs and PCDFs and their weight average chlorination degree in soil and gas. After thermal treatment, the levels of PCDDs in the soil continuously decrease as the temperature rises. PCDFs, however, show a distinct tendency. At $400{ }^{\circ} \mathrm{C}$, their concentration peaks at 1260 $\mathrm{pg} \mathrm{g}^{-1}, 353 \mathrm{pg} \mathrm{g}^{-1}$ higher than in the grinded soil. But at higher temperatures, the amount of PCDFs quickly declined again and maintained comparable values for temperatures reaching 500 or $600{ }^{\circ} \mathrm{C}$.

The weight average chlorination degree of PCDD/Fs in grinded soil is 4.74 and this always rises after thermal treatment. With the rising temperature, the value slightly reduces. This observation can be explained by the fact that the formation

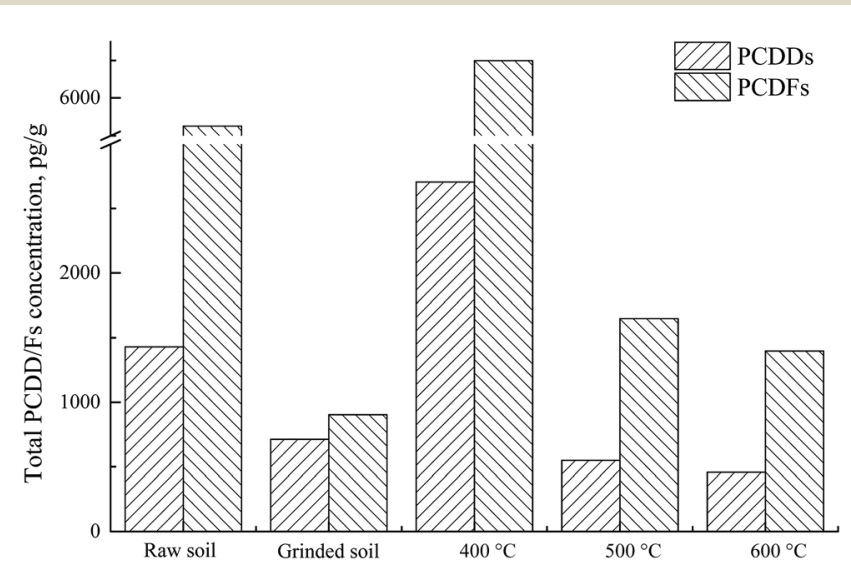

Fig. 3 Total PCDD/Fs concentration both in soil and flue gas.

Table 3 Amount of dl-PCBs in thermally treated soil and flue gas

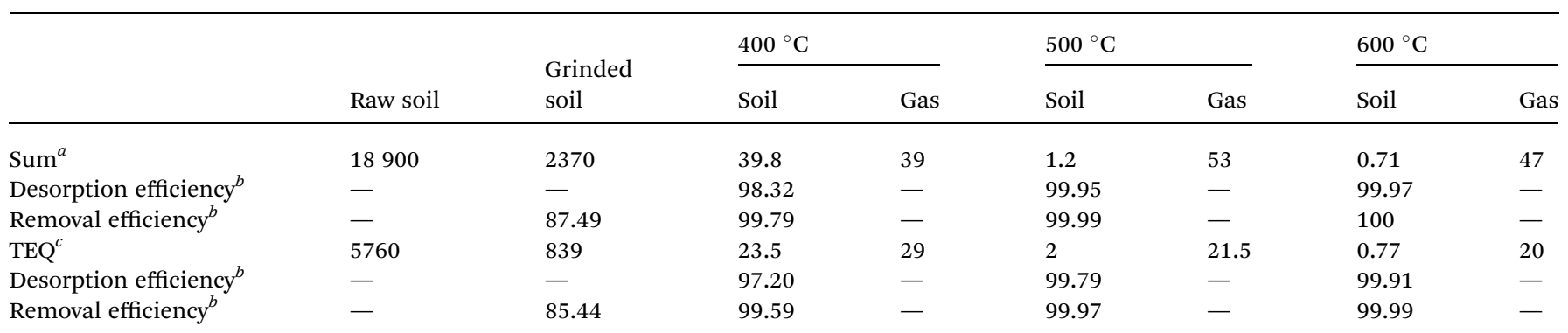

${ }^{a}$ Unit: ng $\mathrm{g}^{-1} \cdot{ }^{b}$ Unit: \%. ${ }^{c}$ Unit: pg WHO-TEQ per $\mathrm{g}$. 
Table $4 \mathrm{PCDD} /$ Fs concentration and chlorination degree in treated soil and flue gas, $\mathrm{pg} \mathrm{g}^{-1}$

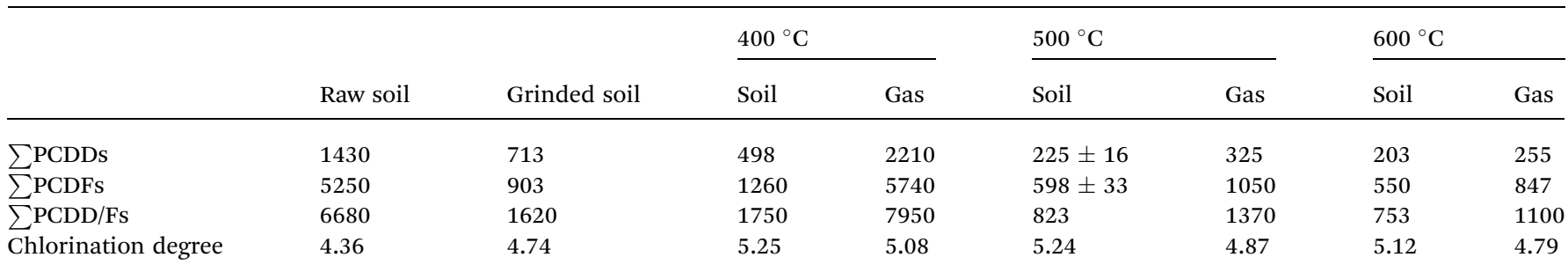

of $\mathrm{PCDD} / \mathrm{Fs}$ weakens at temperatures that are above the optimum temperature range for their generation. ${ }^{39}$ Conversely, the hydrodechlorination reaction is stronger at these higher temperatures.

In the flue gas a maximum concentration of PCDDs and PCDFs also occurs at $400{ }^{\circ} \mathrm{C}$ (Table 4), attaining $2210 \mathrm{pg} \mathrm{g}^{-1}$ and $5740 \mathrm{pg} \mathrm{g}^{-1}$, respectively. When the treatment temperature rises to 500 or $600{ }^{\circ} \mathrm{C}$, decomposition becomes stronger than formation.

The trend of the chlorination degree in the gas phase resembles that in the soil. As treatment temperature increases, the value reduces slightly. All chlorination levels are a little lower in the soil than in the gas phase: formation occurs before the contaminant desorbs from the soil surface and decomposition dominates once the contaminant transfer into the gas phase.

3.3.2 Toxic PCDD/Fs concentration and TEQ in soil and off gas. Table 5 presents the concentration and TEQ-values of the 17 toxic 2,3,7,8-substituted PCDD/Fs. In grinded soil, the sum of these toxic PCDDs and PCDFs was 31.1 and $101 \mathrm{pg} \mathrm{g}^{-1}$, respectively. Four congeners, OCDD, 2,3,7,8-TeCDF, 2,3,4,7,8PeCDF and 1,2,3,4,6,7,8-HpCDF predominate. After thermal treatment, the same tendencies are reflected as with total PCDD/Fs. The maximum concentrations of toxic PCDDs and PCDFs both in thermally treated soil and in the off-gas, were observed at $400{ }^{\circ} \mathrm{C}$ before the concentrations then decreased with the incremental temperature rises. The TEQ of toxic PCDDs and PCDFs shows a similar variation tendency.

PCDD/Fs formation was inevitable during the thermal processing of chlorinated contaminants. In practical thermal remediation processes, higher temperatures were recommended. Hydrodechlorination and the destruction reactions played an important part in the removal of PCDD/Fs when the

Table 5 Concentration and TEQ of toxic PCDD/Fs

\begin{tabular}{|c|c|c|c|c|c|c|c|}
\hline & \multirow{2}{*}{$\begin{array}{l}\text { Grinded } \\
\text { soil } \\
\text { Soil }\end{array}$} & \multicolumn{2}{|c|}{$400{ }^{\circ} \mathrm{C}$} & \multicolumn{2}{|c|}{$500^{\circ} \mathrm{C}$} & \multicolumn{2}{|c|}{$600{ }^{\circ} \mathrm{C}$} \\
\hline & & Soil & Gas & Soil & Gas & Soil & Gas \\
\hline$\sum \operatorname{PCDDs}^{a}$ & 31.1 & 111 & 389 & 47.8 & 28.5 & 33.4 & 22.2 \\
\hline$\sum \mathrm{PCDFs}^{a}$ & 101 & 365 & 1390 & 178 & 204 & 129 & 160 \\
\hline$\sum \mathrm{PCDD} / \mathrm{Fs}^{a}$ & 132 & 476 & 1780 & 226 & 233 & 162 & 182 \\
\hline TEQ- $\sum$ PCDDs $^{b}$ & 8.63 & 10.91 & 72.87 & 6.38 & 4.87 & 4.16 & 0.55 \\
\hline $\mathrm{TEQ}^{-\sum \mathrm{PCDFs}^{b}}$ & 10.31 & 20.05 & 86.31 & 10.78 & 15.93 & 9.11 & 13.40 \\
\hline TEQ- $\sum \mathrm{PCDD} / \mathrm{Fs}^{b}$ & 18.94 & 30.95 & 159.18 & 17.17 & 20.80 & 13.27 & 13.95 \\
\hline
\end{tabular}

temperature was higher than $350{ }^{\circ} \mathrm{C}^{\mathbf{4 0}}$ Alternatively, some appropriate chemical inhibitors could be introduced to suppress the formation of PCDD/Fs during thermal desorption. ${ }^{\mathbf{4 1}}$

\section{Conclusions}

A combination of the mechanochemical pre-treatment and thermal desorption is a feasible alternative for remediating PCBs-contaminated soil, as it reduces remediation time and also achieves a considerable removal efficiency. After ball milling for 2 hours, the total concentration, and the TEQ, of PCBs in the soil decreases by $81.9 \%$ and $85.4 \%$, respectively, and degradation is facilitated by the addition of $\mathrm{SiO}_{2}$.

The temperature of the thermal treatment significantly influences the desorption efficiency of PCBs in the grinded soil. The residual total amount of PCBs in the thermally treated soil decreases as the temperature rises. When the temperature increased to $600{ }^{\circ} \mathrm{C}$, the residual PCBs concentration was $137 \mathrm{ng}$ $\mathrm{g}^{-1}$ and the desorption efficiency reached $99.85 \%$. The removal efficiency, based on the raw soil, reached almost $100 \%$ after the combined treatment. Hydrodechlorination and decomposition occur during desorption, especially at high temperatures.

PCDDs and PCDFs are generated during the thermal treatment process, especially at $400{ }^{\circ} \mathrm{C}$, while formation becomes weaker at higher temperatures. Conversely, the process of hydrodechlorination and decomposition strengthen at these higher temperatures, thereby reducing the residual content of PCDD/Fs.

\section{References}

1 Y. Xing, Y. Lu, R. W. Dawson, Y. Shi, H. Zhang, T. Wang, W. Liu and H. Ren, Chemosphere, 2005, 60, 731-739.

2 Z. Qi, A. Buekens, J. Liu, T. Chen, S. Lu, X. Li and K. Cen, Environ. Sci. Pollut. Res., 2014, 21, 6448-6462.

3 S. Lu, J. Huang, P. Zheng, X. Li and J. Yan, Chem. Eng. J., 2012, 195-196, 62-68.

4 K. Zhang, J. Huang, Z. Wang, Y. Yu, S. Deng and G. Yu, J. Hazard. Mater., 2012, 243, 278-285.

5 Z. Wang, J. Huang, F. Xu, S. Deng, W. Zhu and G. Yu, J. Hazard. Mater., 2011, 198, 275-281.

6 K. Zhang, J. Huang, H. Wang, K. Liu, G. Yu, S. Deng and B. Wang, Chemosphere, 2014, 116, 40-45.

7 Y. Wei, J. Yan, S. Lu and X. Li, J. Environ. Sci., 2009, 21, 1761-1768.

8 S. Saeki, J. Kano, F. Saito, K. Shimme, S. Masuda and T. Inoue, J. Mater. Cycles Waste Manage., 2001, 3, 20-23. 
9 Y. Mitoma, H. Miyata, N. Egashira, A. M. Simion, M. Kakeda and C. Simion, Chemosphere, 2011, 83, 1326-1330.

10 Q. Zhang, H. Matsumoto, F. Saito and M. Baron, Chemosphere, 2002, 48, 787-793.

11 Y. F. Yu, J. Huang, W. Zhang, K. L. Zhang, S. B. Deng and G. Yu, Chemosphere, 2013, 90, 1729-1735.

12 I. W. Nah, K. Hwang and Y. Shul, Chemosphere, 2008, 73, 138-141.

13 Q. Zhang, F. Saito, T. Ikoma, S. Tero-Kubota and K. Hatakeda, Environ. Sci. Technol., 2001, 35, 4933-4935.

14 Y. Wei, PhD Dissertation, Zhejiang Univ, 2010.

15 Z. Zhao, M. Ni, X. Li and A. Buekens, Int. J. Environ. Pollut., 2016, 60, 171-189.

16 R. Weber, T. Takasuga, K. Nagai, H. Shiraishi, T. Sakurai, T. Matuda and M. Hiraoka, Chemosphere, 2002, 46, 12551262.

17 P. Varanasi, A. Fullana and S. Sidhu, Chemosphere, 2007, 66, 1031-1038.

18 J. Liu, Z. Qi, Z. Zhao, X. Li, A. Buekens, J. Yan and M. Ni, Environ. Sci. Pollut. Res., 2015, 22, 19538-19545.

19 T. Sato, T. Todoroki, K. Shimoda, A. Terada and M. Hosomi, Chemosphere, 2010, 80, 184-189.

20 J. Liu, Z. Qi, X. Li, T. Chen, A. Buekens, J. Yan and M. Ni, Environ. Sci. Pollut. Res., 2015, 22, 12289-12297.

21 J. Huang, T. Matsumura, G. Yu, S. Deng, M. Yamauchi, N. Yamazaki and R. Weber, Chemosphere, 2011, 85, 239-246.

22 J. H. Yan, Z. Peng, S. Y. Lu, X. D. Li, M. J. Ni, K. F. Cen and H. F. Dai, J. Hazard. Mater., 2007, 147, 652-657.

23 Y. Tanaka, Q. Zhang, K. Mizukami and F. Saito, Bull. Chem. Soc. Jpn., 2003, 76, 1919-1925.

24 Y. Tanaka, Q. Zhang and F. Saito, J. Phys. Chem. B, 2003, 107, 11091-11097.

25 J. Merino and V. Bucala, J. Hazard. Mater., 2007, 143, 455461.
26 P. P. Falciglia, M. G. Giustra and F. Vagliasindi, J. Hazard. Mater., 2011, 185, 392-400.

27 L. Lundin, J. Aurell and S. Marklund, Chemosphere, 2011, 84, 305-310.

28 Z. Qi, PhD Dissertation, Zhejiang Univ, 2014.

29 Z. Qi, T. Chen, S. Bai, M. Yan, S. Lu, A. Buekens, J. Yan, C. Bulmău and X. Li, Environ. Sci. Pollut. Res., 2014, 21, 4697-4704.

30 Y. Mitoma, S. R. Mallampati, H. Miyata and M. Kakeda, Arch. Environ. Contam. Toxicol., 2013, 64, 180-186.

31 N. He, P. Li, Y. Zhou, W. Ren, S. Fan and V. A. Verkhozina, J. Hazard. Mater., 2009, 164, 126-132.

32 H. I. Gomes, C. Dias-Ferreira and A. B. Ribeiro, Sci. Total Environ., 2013, 445, 237-260.

33 S. Kim, K. Lee, K. Kim, M. Kwon and G. Song, J. Waste Manage., 2007, 27, 1593-1602.

34 P. C. Hung, W. C. Lo, K. H. Chi, S. H. Chang and M. B. Chang, Chemosphere, 2011, 82, 72-77.

$35 \mathrm{~J}$. Liu, Z. Cui and H. Xu, The review of the environmental behaviors of polychlorinated biphenyls (PCBs) in soils and sediments, J. Shandong Univ., 2006, 36, 94-98.

36 M. Van den Berg, L. S. Birnbaum, M. Denison, M. De Vito, W. Farland, M. Feeley, H. Fiedler, H. Hakansson, A. Hanberg and L. Haws, Toxicol. Sci., 2006, 93, 223-241.

37 K. Olie, P. L. Vermeulen and O. Hutzinger, Chemosphere, 1977, 6, 455-459.

38 M. Yan, X. Li, T. Chen, S. Lu, J. Yan and K. Cen, J. Environ. Sci., 2010, 22, 1637-1642.

39 M. B. Chang and T. F. Huang, Chemosphere, 2000, 40, 159164.

40 H. Wu, S. Lu, J. Yan, X. Li and T. Chen, Chemosphere, 2011, 84, 361-367.

41 Z. Zhao, M. Ni, X. Li, A. Buekens and J. Yan, Environ. Sci. Pollut. Res., 2016, 23, 25335-25342. 